\title{
3D ARCHITECTURAL VIDEOMAPPING
}

\author{
R. Catanese \\ Dept. of History of Art, Digital Technologies for Performing Arts, Sapienza University of Rome, Italy - \\ rossella.catanese@uniroma1.it
}

KEY WORDS: 3D, Videomapping, Performing Arts, Post-cinema studies, Digital art, Audio-visual art.

\begin{abstract}
:
3D architectural mapping is a video projection technique that can be done with a survey of a chosen building in order to realize a perfect correspondence between its shapes and the images in projection. As a performative kind of audiovisual artifact, the real event of the 3D mapping is a combination of a registered video animation file with a real architecture. This new kind of visual art is becoming very popular and its big audience success testifies new expressive chances in the field of urban design. My case study has been experienced in Pisa for the Luminara feast in 2012.
\end{abstract}

\section{INTRODUCTION}

\subsection{D architectural videomapping}

This paper introduces 3D architectural mapping in a Visual Studies perspective; as a new kind of art form, and as a product of an historical path. In the realm of digital technologies for performing arts and humanities, this short essay focuses on the description of a video projection technique. As a performative kind of audiovisual artifact, the real event of the 3D mapping is a combination of a registered video animation file with a real architecture. This new kind of visual art is becoming very popular and its big audience success testifies new expressive chances in the field of urban design. My case study will focus on a videomapping show realized in Pisa for the Luminara feast in 2012 .

The idea of proposing an ephemeral festive apparatus defines an avant-garde project, read as a new kind of development of the cultural heritage, through the huge chances of sophisticated technologies and through the contemporary audience's new requirements, towards interactivity, animation and the threedimensional features of moving images.

Modern technologies of animation allow us to recreate striking effects of three-dimensional visual movements. It is necessary to study every detail of surface, such as windows, columns or other elements. Later, through a detailed reconstruction, compositing and animation, it will be possible to create effects of light to create imaginary figures, interacting through movement with the historical static of the building and using every detail as a pretext to design dynamic elements, livening up the visual composition.

This new kind of visual art is becoming very popular and its big audience success testifies new expressive chances in the field of urban design. If the visual mapping is the contemporary version of tromp l'oeil effects or son et lumière shows, it will be possible to reflect on issues of identity inside the relationship among the contemporary urban imagery and the current 'mediascape', quoting Arjun Appadurai.

\subsection{Description and applications}

Videomapping is emerging as a projection technique that transforms any surface (buildings, surfaces, and almost all kinds of complex surfaces or three-dimensional objects) in a dynamic display: from large images on monuments or facades, up to virtual worlds. We could define it as a projection technique on three-dimensional surfaces, that allows us to explore the creative potential of digital technologies as synesthetic means. It utilizes new concepts in three-dimensionality and reversibility to perform a syncretic technique that deals with moving images, computer graphics and historical architecture. Looking over the practical applications of this technique, you can consider that often technologies and new discoveries come out from their scientific framework and become different forms of art, improving their expressive means. These art forms dialogue also with the entertainment paradigm, allowing the artists to experiment more sophisticated works.

The word originates from the three-dimensional mapping of buildings (Architectural Mapping) that allows us to trace the elements of the facade and the architectural geometry, with the support of 3D technologies and laser scanning. ${ }^{1}$ This technology is being tested in the surveys of architectural facades for preliminary study of restorations and renovations. It is necessary to specify a clear definition, because videomapping is also the name of another technique, used in geo-localization, for taking notes in the form of images, shooting the road travelled with a video camera placed on a car, and processing data for the maps on Internet or GPS.

The videomapping (called also "Video Projection Mapping", "3D Projection Mapping", "Projection Mapping", "Digital Mapping”, "Architectural Mapping") is an experimental developing technique. Its different applications are innovative forms of multimedia art.

The use of proper software allows you to create animations, images, videos and plays of light customized in order to "play" with the surface on which they are projected. Combined with audio equipment, you can "tell a story" or let the audience live it a synaesthetic experience (today it would rather used the definition of an "emotional" experience). Unlike simple projection on a screen, the videomapper interacts with the display surface, offering it a new reading.

\footnotetext{
${ }^{1}$ Laser scanning is a new technology, used since 1998 and soon become an industrial standard, for getting accurate measures in complicated environments and buildings. A 3D digital device (laser line scanner) project a laser light on a surface while cameras triangulate variations in distance and shape of the laser line when it flows, quickly digitizing the object in three dimensions.
} 
The software can manage how to bend and highlight any line, shape, or space, and creates amazing optical illusions and evocative light, turning a physical object in something else, changing the perception of shapes.

\section{HISTORY}

In art history, avant-garde artists have always drawn from new techniques, tools and materials, to express their insights; now videomapping is a technique that comes from a perspective of our time and the current mediascape.

Digital culture and new media framework are its recent background, but videomapping has an older cultural tradition. According to philosopher Paul Virilio it is impossible to separate history of visual shows from history of artificial light, for their technological affinity. An historical precedent of videomapping can be recognized in fireworks or luminarias, used in popular feasts related to agricoltural flows. The use of light in magical or religious rituals that emphasizes the profiles of churches and statues of saints, giving them a sacred look, is deeply rooted in popular imagery. The suggestion of light fascinates even the French nobility of the Baroque era. The archetype of the "light designer" was born in the seventeenth century. He edited the night lighting of gardens, places of leisure. The artificial light that illuminates the baroque feasts creates a special atmosphere.

In the eighteenth century the English Pleasure Gardens, "gardens of delight", (Richardson, 2008) offered the viewer light and music shows: an experience of pleasure towards the sublime.

In the twentieth century a more refined entertainment, "Son et Lumière", inherits the ancient of the light shows. These are performances - usually nocturnal and outdoor - involving the lighting of a monument accompanied by a musical evocation of its history. This "performance without actors" combined with an architecture of light was born in the early 50 s in France (in particular, in the castles of the Loire), and then extends to the whole world. An example of light show derived from a religious cult is the "Festival of Lights" in Lyon (formerly Feast of 8th December) which, from a religious procession, in 1989 has become a huge event of light installations. With the advent of digital the videomapping has a fast rising: projectors are designed to display TV programs and PC video formats; in recent years, the emergence of digital cinema offers fresh impetus to the production of projectors specifically designed for cinema.

Videomapping owes a debt of gratitude to a very ancient painting technique: the trompe l'oil. Used since the Greeks and Romans both decorated their houses, making a virtue out of necessity (a marble painted capital costs less than real marble), and to virtually expand closed environments, at the same time.

Bruno Munari (1907-1998), Italian designer, close to Futurism avant-garde in his early years, and experimenter of new art forms, anticipated the modern multimedia video installations. In particular, the "programmed art optics", which is ahead of the video art. Munari researched the increasing separation between pure art and art production, linked to the needs of big industry and mass consumption. In the fifties, Munari anticipated the dematerialization of works of art (Danto, 1998) and creates the "Direct Projections", then screened at MOMA in New York (Munari's Slides). They are small compositions, collage of organic materials or plastic, inserted between two glass slides and projected on the walls in big dimensions: real "bright paintings", a visual stimulation of the viewer that experimented with new effects of light and color. In Italy Munari has not been followed in this path, even when he managed to make the three- dimensional projections with polarized light rather than direct light.

The first known record of projections onto 3D objects was in 1969, when Disneyland opened their Haunted Mansion ride. It has been used a setting of fake disembodied heads as objects which had $16 \mathrm{~mm}$ film projected onto their surface, in order to make them look real through optical illusions. Another record of a projection mapping is dated 1980, when the artist Michael Naimark filmed people interacting with objects in a living room, then projected it in the same room, creating illusions as if the people interacting with the objects were actually there.

The first time the concept of projection mapping that was investigated academically was at the University of North Carolina at Chapel Hill, in the late 1990s, where scholars worked on the project Office of the Future. In this project, they wanted to connect offices from different locations to feel as if they were together in a shared office space by projecting people into the office space as if they were really there. ${ }^{2}$

We can consider video art the closest ancestor of the videomapping. Video art was experimented by the AmericanKorean Nam June Paik, participating in the neo dadaist movement Fluxus. Fluxus manifesto (1963) was processed from Lithuanian George Maciunas, who spread the virus of total art between Europe and America. In Italy, the history of video art, such as language and means of expression, has been made by Florentine project Art/tapes/22, that from '72 to '76 became a vanguard in the world. The video art of the $60 \mathrm{~s}$ and $70 \mathrm{~s}$, which used technology towards a new imagery, had got mainly from radio, electronic music, comics and new drama. But also in popular framework it has been experienced a new way of visual show. In the mid-Sixties in the USA "liquid light shows" spread. The audience was looking for new experiences, so it has been tested special effects related to music or just decorative, such as lights projected on smoke, reflective disco balls, slide shows. In the Seventies the video jockey (VJ) appeared in New York clubs which became popular on MTV. The VJing, namely the creation and manipulation of images in sync with the music, was born as a live performance in concerts and discos, sometimes in association with other performing arts, in order to create a synesthetic experience of vision and sound. During the 80s there has been a transition to post-modern: para-literary models of cultural interpretation gave way to new sensibilities, to the audio-visual hybridization of the dawn of the digital multimedia. The English videomusic, the Italian videotheatre, the intermedia experiments of electronic arts converged in "techno" cultures and VJ in particular, invest public space of a new audio-visual synesthesia. The video comes out of the screen, marking the space with incorporeal symbols.

The videomapping has its roots in street art and graffiti, stencil, urban installations, wheat pasting, stickering, moss graffiti, laser tags (Kuittinen, 2010), underground phenomena which reinvents the use of the urban walls as media, often for political aims. The urban landscape becomes a new territory to act perceptual and interactive experiences: graffiti art, tag-art, architectural lighting and multimedia installations, they are all new ways to communicate emotionally a monument or a place. Definitely videomapping is son of a digital "new rhetoric". We are experiencing the emergence of a new visual language, hybrid of cinema, printed word, HCI, entertainment; a kind of contemporary Esperanto. The human-computer interface, semiotic code inseparable from any content of current cultural objects and artistic creations, plays a crucial role in the information society.

A digital medium implies a transcoding process which uses

${ }^{2}$ Office of the future: http://www.cs.unc.edu/Research/stc/index.html last visit 09/07/2013. 
calculation by discrete, discontinue values, turning light waves into numeric units (from digit $=$ decimal number). Even if digital system is a completely different structure of representation, these media are now in a transition age. The introduction into the images system of the numeric information allows operations on the image with a wide flexibility of action, although it is bound to numeric encoding and decoding systems. The information is managed by the device which converts the numerical sequence in visible unit. Digital technology ensures data repeatability without alterations and a high potential of intervention on data.

\section{HOW TO MAKE A VIDEOMAPPING}

There are at least two ways to make videomapping:

A) Preparing the images to be projected on a surface/facade. The images can be projected using the building as a huge flat screen. The building itself creates a mask and there is no need to make a calibration, usually required;

B) Working on the masking, i.e. preparing masks (a kind of opaque pattern) with the exact shape and position of the various elements of the surface/facade. The video is projected on these masks, or in the space between the masks, using a simple alphachannel technique (a way to specify the degree of opacity of a clip).

Using a single projector you can have a two-dimensional image, not aligned to the building. With multiple projectors (calibrated along the surface that acts as a display, and properly driven) you might create a three-dimensional effect. The new generation projectors, with a single goal but the same number of pixels two ${ }^{3}$, can project a large image, overcoming this limitation.

Basically a performance of videomapping is prepared in six steps: data acquisition (display), data processing (display/projector); creation (sound/video design), test (possibly on the display); reworking; projection.

The most important equipment for the videomapping is the projector. Its power must be proper (short/long range): for small objects or environments it needs at least a brightness of 5,600 lumens, and up to 20,000 lumens for clear and precise images over large areas or long distances.

You also need a camera with a good lens, so you can adjust the lens to match as much as possible to the lens of the projector (in order to control the tilt of the lens and the angle of view), it should be placed on or very close to the projector, located on the front projection area.

Before starting the test for calibration - getting the correspondence between the three-dimensional coordinates of the real world and those of our virtual model - a laser tool may be useful to measure distances and a bubble level for a perfect and stable positioning horizontal projector. The problem of correspondence to the real world with its virtual counterpart ("match moving" or "camera tracking" in cinematography) can be solved with software for tracking or with projectors that enable self-calibration. The manual set-up helps for good results: the image plane must be perpendicular to the axis of the lens. An important factor to consider for visual effects is "the point of view of the projector": the more this coincides with the point of view of the viewer and the more accurate the projected image will be more accurate, less distorted. Using a photo editing software you may set the photo size in proportion to the resolution of the projector.

Then you need to generate a virtual copy of the real

\footnotetext{
${ }^{3}$ For instance, the F35 panorama projector (2560x1080 pixel, 21:9) allow the view of two images placed side by side in very high definition, avoiding infrastructures and activities related to the management of two separate projectors for creating a unique image.
}

environment for projection, through measurements (triangulation method) and modelling (get a "cloud of points" with the three-dimensional coordinates, and process the data to complete the model). The result of combining photos, computer modelling, detection is a bi- or three-dimensional homographic survey of the object in a virtual environment.

At this point you can edit the masking (masking), also "in motion", with a dedicated software. For each mask, you may cut the different elements of the image to get the templates, patterns that will be used separately. The editing of the images through the masks has to be combined with a sound track; this combination is allowed by $\mathrm{VJ}$ software.

The most important parameter is the maximum resolution of the projector, depending on the distance and size of the images, to be taken as a guideline for the entire project. The next step, the most delicate and difficult of the workflow, is the production of a model of the surface that will be the dynamic display of the screening, with its reference points.

Instead the most creative phase is what we could define visual design and sound design: then you should check that the wanted effects will be correctly seen and perceived by the user, by studying carefully the positioning of the projector and the audio speakers.

Therefore, in order to realize a videomapping project, you need a preliminary feasibility research, then specific skills (video design, sound design, interactive design) and a deep knowledge of compositing, 3D graphics, 3D polygonal modelling, video editing, motion graphics, texturing, lighting e rendering, and also basic knowledge of cinema and photography.

But the entire management of a project needs to deal with external relations (customer, supplier, copyright holdings, institutions, sponsors), involving also other skills.

\section{CASE STUDY: LUMINARA FEAST IN PISA}

As a case study, I introduce the 3D videomapping presented in Pisa (Tuscany, Italy) for Luminara, St. Ranieri's patronal feast. I collaborated to a project realized in 2012 by the artist Piero Fragola.

Luminara (also known as Luminaria) is a festival of light in Pisa, with the UNESCO patronage. Every year, on June 16 for the feast of the city's patron saint, San Ranieri, the riverside of Pisa is lit up by thousands of lights and candles at dusk. The transfer in 1688 of the urn of Saint Ranieri degli Scaccieri (dead in Pisa in 1161) provided for the setting up of a lighting architecture able to redesign the buildings of the Arno river; every year about 100,000 candles (in Pisa "lampanini") are placed on wooden frames (called "biancheria", Italian for linen) going to draw the architectural shape of churches, palaces and towers of the riversides. So a strong local identity is related to a larger Italian custom that in the Baroque period provided ephemeral installations and festive apparatuses (Carandini, Fagiolo dell'Arco, 1978).

This project proposes a scenographic dressing based on the concept of light as a means of writing the space, in a plain analogy with the spirit, the structure and raison d'etre of the baroque feast.

The idea of re-proposing an ephemeral festive apparatus defines an avant-garde project that matches with Pisa's history and aesthetics, for the strong continuity of identity with the tradition. The chosen place is Palazzo Pretorio (Praetorian Palace), due to its strategic position between Lungarno Galileo Galilei and Lungarno Gambacorti, the heart of the event. Its shape and the clock tower make it an ideal subject for many animated images. We carried out a survey of every detail of the facade, windows, columns, and the clock, analyzing the set of the composition of 
the building, the distribution of shapes and shadows, the alternation of full and empty spaces, symmetries.

The pure forms and geometries of the Tuscan tradition are activated and animated by a series of digital animation and compositing operations, which interact through movement with the static nature of the historic building.

The principle of the organic with the surrounding urban environment and the traditional feast maintains a uniform look in color choices. The colors of our projection, while varying tones of more delicate effects almost fluorescent, explore the warm tones of the flames, just like the candles that decorate the palaces of the Arno river.

The windows come alive and begin to play with music, alternating light and dark. The tower and clock, the most relevant and connotative architectural elements of the palace, become a pretext to redraw dynamic elements, adding vitality to the visual composition, which adds to the physical space and material space narrative and performative.

The windows come alive and begin to play with music, alternating light and dark. The tower and clock, the most relevant and connotative architectural elements of the palace, become a pretext to redraw dynamic elements, adding vitality to the visual composition, which adds to the physical space and material space narrative and performative.

Vibrating flames make evanescent what they enlighten. The drawn environment is seen from the point of view of a flame, illuminating a rarefied atmosphere. A choreography of bright spots, then, builds a virtual constellation that re-works the structure of the building in a futuristic three-dimensional composition. The balls of fire light up the architecture of the facade recalling the spectacular fireworks, symbolically carrying the sky on the surface of the building and then inside its windows. Then the show performed other simulations headlights, experimenting with the possibility of redesigning a chiaroscuro, light and shadow that interact with the structure and animate the centennial plates, windows and columns. Or proposing an ancient colonnade and inserting a bell in the tower. Then the building turns in a tree, with flowery flames, symbols of the feast.

\section{CULTURAL HERITAGE}

The videomapping is one of the most ephemeral contemporary art forms; for this reason we have additional problems for documentation and archiving. Like other events with a strong performative character, theatrical or video installations, the memory of the event is delegated to video recordings of the occurred screening, leading to a gap between actual public use of the event and its recording.

As aforementioned, this is a dialogue between a historical past, related to the characteristics of the historical buildings, and a technological present, in which in which special effects with a high coefficient of simulation are used to dramatically manipulate the image, to rewrite and redesign it. Heirs of sensory experiences 'immersive' demonstrations optical spectacular, from magic lanterns to kaleidoscopes, from the diorama to the 'cinema of attractions', digital special effects have emulated the existing filmic techniques, in a short circuit even in archival practices.

In the era of audiovisual obsolescence, in which every product of industry and culture of the moving image is recorded, documented and archived, primary importance is given to conservation methods, which determine a trace in memory. What Hal Foster and Mary Ann Doane both call "the archival impulse" (Foster, 2004; Doane, 2002) is the drive to preserve something of the present, a kind of imperative that leads to the anticipation of the future and it is a characteristic feature of digital civilization. We have not found effective solutions yet to archive properly these new linguistic formulas of contemporary cultural heritage.

The immersion of the so-called post-medial movie, those filmic forms that are not consumed in the movie theater, but in everyday life, in a process of expansion, is transforming the physical landscape in a space of vision. Video installations in museums, software of geo-location in smartphones, the audiovisual scenery have modified their connotations creating new symbolic worlds. The famous proposal of Virilio «Cinema isn't I see, It's I Fly» is a suggestive way to evaluate technological implications of urban cinema. Cinema as technology developed in an urban space: in its architecture cities are conceived as cinematographic set; there is no difference between normal citizens and walk-on actors. Now we can consider the urban landscape as the proper object whence new light plays and living audio-visual shows arise.

\subsection{Illustration}

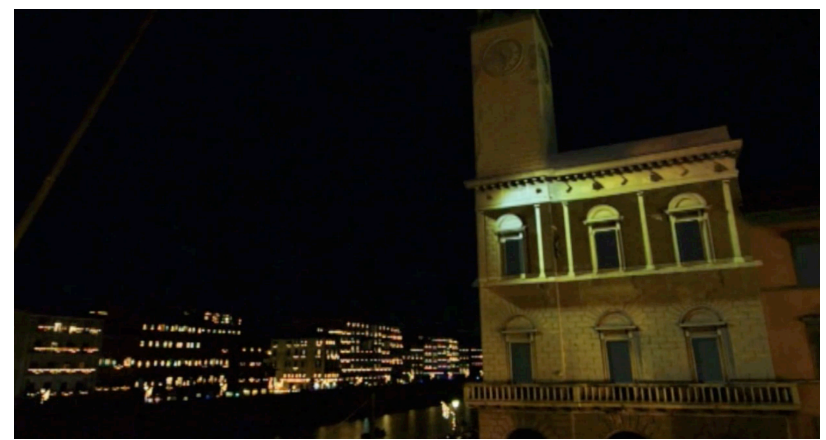

Figure 1. Videomapping for the Luminara (Pisa 2012)

\subsection{Selected Bibliography}

Briggs, A., Burke, P., 2002. A social history of the media: from Gutenberg to the Internet, Polity, Cambridge.

Carandini, S., Fagiolo Dell'Arco M., 1978. L'effimero barocco. Strutture della festa nel Seicento, Bulzoni, Roma.

Danto, A. C., 1998. Beyond the brillo box : the visual arts in post-historical perspective, University of California Press, Berkeley.

De Rosa, M., 2013. Cinema e postmedia. I territori del filmico nel contemporaneo, Postmedia Books, Milano.

Doane M. A. 2002. The Emergence of Cinematic Time. Modernity, Contingency, the Archive, Harvard University Press, Cambridge-London.

Fossati, G., 2009. From Grain to Pixel. The Archival Life of Film in Transition, Amsterdam University Press, Amsterdam.

Foster, H., 2004, An Archival Impulse. October 110, pp. 3-22.

Grau, O., 2003. Virtual Art. From Illusion To Immersion, MIT Press, Cambridge-London.

Krauss, R., 2000. Voyage on the North Sea: Art in the Age of the Post-Medium Condition, Thames \& Hudson, London. 
Kuittinen, R., 2010. Street art: contemporary prints, V\&A Publishing, London.

Manovich L., 2001. The Language of New Media, MIT Press, Cambridge.

Menduni E., 2013. Entertainment. Spettacoli, centri commerciali, talk show, parchi a tema, social network, Il Mulino, Bologna.

Menduni E., 2007. I media digitali: tecnologie, linguaggi, usi sociali, Laterza, Roma-Bari.

McLuhan, M., 1964. Understanding Media: the Extensions of Man, New American Library, New York.

Montani, P., 2010. Immaginazione intermediale, Laterza, Roma-Bari, 2010.

Munari, B., 2007. Fantasia: invenzione, creatività e immaginazione nelle comunicazioni visive, Laterza, Roma-Bari.

Richardson, T., 2008. Avant gardeners: 50 visionaries of the contemporary landscape, Thames \& Hudson, New York.

Rodowick D., 2003. The Virtual Life of Film, Harvard University Press, Cambridge - London.

Thorburn, D., Jenkins, H., (eds) 2003. Rethinking Media Change: The Aesthetics of Transition, MIT Press, Cambridge MA.

Virilio, P., 1984. Guerre et cinéma: logistique de la perception, Cahiers du cinéma, Éditions de l'Étoile, Paris.

\subsection{Acknowledgements}

Special thanks to Piero Fragola, author of the 3D videomapping show realized in Pisa for the Luminara feast 2012. 